\title{
Electrostatic immobilization of antimicrobial peptides on polyethylenimine and their antibacterial effect against Staphylococcus epidermidis
}

\author{
J. Hernandez-Montelongo ${ }^{\mathrm{a}, \mathrm{b}, \mathrm{c}, *, 1}$, Y.R. Corrales Ureña ${ }^{\mathrm{d}, 1}$, D. Machado $^{\mathrm{e}}$, M. Lancelloti ${ }^{\mathrm{e}}$, \\ M.P. Pinheirof ${ }^{f}$, K. Rischka ${ }^{\text {f }}$, P.N. Lisboa-Filhog ${ }^{g}$, M.A. Cotta ${ }^{a}$ \\ a Departamento de Física Aplicada, Instituto de Física Gleb Wataghin, Universidade Estadual de Campinas, 13083-859 Campinas, Brazil \\ b Departamento de Ciencias Matemáticas y Físicas, Facultad de Ingeniería, Universidad Católica de Temuco, 4813302 Temuco, Chile \\ c Núcleo de Investigación en Bioprodructos y Materiales Avanzados (BioMa), Facultad de Ingeniería, Universidad Católica de Temuco, 4781312 Temuco, \\ Chile \\ d Laboratorio Nacional de Nanotecnología, Centro Nacional de Alta Tecnología, 1174-1200 San José, Costa Rica \\ e Faculdade de Ciências Farmacêuticas, Universidade Estadual de Campinas, 13083-871 Campinas, Brazil \\ ${ }^{\mathrm{f}}$ Fraunhofer Institute for Manufacturing Technology and Advanced Materials, 28359 Bremen, Germany \\ ${ }^{g}$ Departamento de Física, Faculdade de Ciências, Universidade Estadual Paulista, 17033-360 Bauru, Brazil
}

\section{A R T I C L E I N F O}

\section{Article history:}

Received 25 October 2017

Received in revised form 29 January 2018

Accepted 2 February 2018

Available online 5 February 2018

\section{Keywords:}

Electrostatic immobilization

Antimicrobial peptides

Staphylococcus epidermidis

\begin{abstract}
A B S T R A C T
Staphylococcus epidermidis is a gram-positive bacterium, and one of the most prevalent causes of nosocomial infections due to its strong ability to form biofilms on catheters and surgical implants. Here we explore the antimicrobial properties of Tet-124 peptides, which are part of the innate defense against different multicellular organisms in nature. Two different Tet-124 peptides were immobilized on a polyethylenimine (PEI) film to determine their impact on the antimicrobial properties: KLWWMIRRW (Tet-124), which contains only natural amino acids, and KLWWMIRRWG-(F-Br)-G (F$\mathrm{Br}=4$-Bromophenylalanine), a modified Tet-124 sequence with the addition of an unnatural amino acid. The immobilization was obtained as a result of the electrostatic interaction between PEI amino groups and the C-terminal carboxylic groups of tryptophan and glycine amino acids of Tet-124 and Tet-124-Br peptides, respectively. The process was monitored and studied by water contact angle, Atomic Force Microscopy (AFM), X-ray Photoelectron Spectroscopy (XPS) and Quartz Crystal Microbalance with Dissipation (QCM-D) measurements. The antibacterial effect of our samples against S. epidermis was evaluated by the spread plate counting method, and cytotoxicity was tested using fibroblast cultures. Our results indicate the feasibility to immobilize electrostatically both Tet-124 peptides for biomedical applications

(C) 2018 Elsevier B.V. All rights reserved.
\end{abstract}

\section{Introduction}

The design of material surfaces, functionalized with bioactive compounds, has seen rapid growth over the past decade in many industries including biomedicine, textiles, microelectronics, bioprocessing, and food packaging. In the field of biomaterials, extensive efforts have been directed to develop functionalization

\footnotetext{
* Corresponding author at: Departamento de Ciencias Matemáticas y Físicas, Facultad de Ingeniería, Universidad Católica de Temuco, 4813302 Temuco, Chile.

E-mail addresses: jacobo.hernandez@uct.cl, jacobo@ifi.unicamp.br (J. Hernandez-Montelongo).

1 These authors contributed equally to this work.
}

that is able to prevent bacterial surface attachment and growth in order to safeguard against infections and device failure [1].

Antimicrobial peptides (AMPs) are known for their broad antimicrobial activity against gram-positive and gram-negative bacteria [2]. They are produced by the immune system of all multicellular organisms [3], which store and secrete antibiotic peptides that can be immediately set into action when infections occur [4]. AMPs have been proposed as an alternative to classic antibiotics for overcoming problems such as multidrug resistant bacteria [5]; moreover, the diversity of peptide sequences also provides no cross-resistance in clinical use [6].

In general, AMPs are amphiphilic molecules with a high content of cationic and hydrophobic amino acids that are responsible for the antibacterial activity [7]. They carry a net positive charge, with an average value of +4 for the known antimicrobial peptides under 
physiological conditions. AMPs can generate stress when in contact with the bacteria cell membrane; metabolic functions and cellular processes may thus be altered [7]. The permeability for ions and proteins transport could be affected [8], and rearrangements and segregation of the lipids and interfacial groups can occur [9]. These changes are driven by the electrostatic interactions between the positively charged amino acids and the negatively charged membrane of bacteria, as well as with lipopolysaccharides (LPS) and acidic polysaccharide molecules in the case of Gram-negative and Gram-positive bacteria, respectively [10]. These interactions can disturb the membrane surface tension, affecting the cell transport and osmoregulation, which will eventually result in its death [9]. Depending on their affinity to different binding sites, AMPs can displace cations such as $\mathrm{Mg}^{2+}$ and $\mathrm{Ca}^{2+}$; their interactions with deoxyribonucleic acid (DNA) and ribonucleic acid (RNA) enzymes and proteins are a promising alternative regarding the mode of action in comparison to classic antibiotics [8].

Both physical and covalent binding have been investigated for peptide immobilization. The developed strategies include layerby-layer deposition mainly driven by electrostatic interactions between the positively or negatively charged surfaces with the peptide, building molecular structures of polycations and polyanions [11]; interaction of specific molecule moieties that can form hydrogen bonding, as in the case of titanium surfaces with DOPA (3,4-dihydroxyphenylalanine) containing antimicrobial peptides [12]; and reaction with silanes [13], among others. On hydrophobic surfaces, the peptides can self-assemble, mostly due to their hydrophobic amino acids. Although the non-covalent interactions are weaker than covalent bonds, the formed films can be stable, depending on the peptide-surface system and experimental conditions [11-14].

In that sense, this work is about the electrostatic immobilization process of AMP on the top of a polyethylenimine film. The AMPs used for the immobilization were based on the Tet-124 peptide [15]: Tet-124 (KLWWMIRRW) and Tet-124-Br (KLWWMIRRWG-(F-Br)-G). Previous works have proposed that electrostatic interactions can be a way to tune the peptide binding on surfaces. For example, Donatan et al. [16] studied the interaction between the 3rGBP1 peptide and the gold surface under several surface charge densities. These authors proposed that anionic side chains of the peptide were oriented to the positively polarized substrate, and vice versa, cationic side chains of the peptide were oriented to the negatively polarized surface. Another interesting work was developed by Baio et al. [17]. They studied the cytochrome C (CytoC) immobilization via electrostatic interactions onto amine and carboxyl functionalized gold substrates. The authors showed that when CytoC interacts with the amine functionalization (positively charged surface), the protein is oriented with the heme group in an opposite direction from the substrate; and when CytoC interacts with the carboxyl functionalization (negatively charged surface), the protein is oriented with the heme group pointed down towards the substrate.

In contrast, Tet-124 peptide was previously covalently immobilized on a cellulose membrane by Hilpert et al., who showed inhibition for the Pseudomonas aeruginosa strain H1001 [15]. In our case, the model microorganism used was Staphylococcus epidermidis, which is a gram-positive bacterium, and one of the most prevalent causes of nosocomial infections [18]. S. epidermidis is particularly problematic due to biofilm formation on catheters and other surgical implants [18]. The strategy of Tet-124 peptide immobilization was planned to orient the positive amino acid residues away from the linker site for enhanced antimicrobial activity. The peptide containing Bromo-phenylalanine can undergo metal-catalyzed reaction under mild conditions [19], opening new possibilities for future coupling reaction of the peptide and other molecules and immobilization on surfaces. The samples were characterized using sensitive surface techniques as water angle contact, Atomic Force Microscopy (AFM), X-Ray Photoelectron Spectroscopy (XPS) and Quartz Crystal Microbalance with Dissipation (QCM-D) to determine changes in the chemical composition and topography of the samples. Our study determined the antimicrobial properties of the immobilized peptides against $S$. epidermidis, and their cytotoxicity was tested using fibroblast cells.

\section{Materials and methods}

\subsection{Solid-phase peptide synthesis}

The peptides Tet-124 and Tet-124-Br were synthesized with a 433A solid-phase peptide synthesizer (Applied Biosystems, USA) using the FastMoc ${ }^{\mathrm{TM}}$ protocol [12]. The syntheses were carried out in a $0.1 \mathrm{mmol}$ scale using either Fmoc-Glycine or Fmoc-Tryptophan (Boc) preloaded tritylchloride resin (TCP). The amino acids were obtained from IRIS Biotech, Germany. TCP resins were purchased from Intavis AG, Germany, with a loading of approx. $0.55 \mathrm{mmol} / \mathrm{g}$.

The cleavage and removal of the side chain protecting groups of the peptide from the resin was performed with a solution consisting of $3600 \mu \mathrm{L}$ trifluoroacetic acid, $200 \mu \mathrm{L}$ deionized water, and $200 \mu \mathrm{L}$ triisopropylsilane. After the synthesis, the resins were treated with the cleavage solution for two hours. The peptides were obtained through precipitation of the cleavage solutions in $60 \mathrm{~mL}$ ice cold tert.-butyl methyl ether after filtration through a syringe filter (polytetrafluoroethylene membrane, diameter $13 \mathrm{~mm}$, pore width $0.45 \mu \mathrm{m}$ ). After centrifugation the precipitates were separated from the ether solution and dissolved in deionized water; the peptides were obtained after lyophilization as a colorless powder.

\subsection{Peptide characterizations}

The purity of the peptides was determined by using a BioCad 700E Reversed-Phase High-Performance Liquid Chromatography system (RP-HPLC) (Applied Biosystems, USA), with a column Polaris $5 \mathrm{u} \mathrm{C18}-\mathrm{A}, 250 \times 4.6 \mathrm{~mm}$ [12]. The peptides were characterized in a time-of-flight mass spectrometer (MALDI-ToF-MS) Voyager DE-Pro (Applied Biosystems, USA) (matrix: $\alpha$-cyano-4-hydroxycinnamic acid [CHCA]) (Sigma-Aldrich, Germany); the purity of the obtained peptides was $95 \%$ or higher. Both peptides were stored at $-20^{\circ} \mathrm{C}$. 3D models of peptides were performed by UCSF Chimera Software V. 1.11.2.

\subsection{Substrate preparation}

Silicon wafers were cleaned by ultra-sonication in acetone, isopropanol, and distilled water for a period of $15 \mathrm{~min}$ in each solvent. Afterwards, wafers were dried under $\mathrm{N}_{2}$ flow and subsequently treated with $\mathrm{O}_{2}$ plasma at 100 mTorr for 15 min (Harrick Plasma Cleaner, PDC-32G). The substrates were obtained by coating the oxidized silicon wafers with a polyethylenimine film (PEI, 50 wt. \% solution in water, $\mathrm{M}_{\mathrm{W}} \approx 7.5 \times 10^{5} \mathrm{~g} / \mathrm{mol}$, Sigma-Aldrich, USA). Previously, a PEI solution was prepared by dissolving the polymer at a concentration of $1 \mathrm{mg} / \mathrm{mL}$ in a $0.5 \mathrm{M} \mathrm{NaCl}$ solution and its $\mathrm{pH}$ was adjusted to 4 with a $0.1 \mathrm{M} \mathrm{HCl}$ and/or $\mathrm{NaOH}$ solution. Then, the PEI film was deposited on the silicon wafers using an automatic dipping procedure (ECSIA NanoScience, Brazil) with constant stirring under room conditions. Wafers were immersed in the PEI solution for $15 \mathrm{~min}$, followed by three consecutive Milli-Q water rinse steps of 2,1 , and $1 \mathrm{~min}$, respectively. The $\mathrm{pH}$ of water rinse was previously set at 4 units. 


\subsection{Immobilization of peptides}

Both peptides were dissolved in a $0.01 \mathrm{M}$ phosphate-buffered saline (PBS) (0.138 M NaCl, $0.0027 \mathrm{M} \mathrm{KCl}, \mathrm{pH} 7.4)$ at $50 \mu \mathrm{g} / \mathrm{mL}$. Then, PEI substrates were sterilized by UV light for $30 \mathrm{~min}$ and immersed in the freshly prepared peptide solutions for $15 \mathrm{~min}$. The samples were rinsed with deionized water and dried under $\mathrm{N}_{2}$ flow.

\subsection{Substrate characterization}

In order to monitor the cascade process from substrate preparation to immobilization, water contact angles of the different samples were determined by using a contact angle goniometer (Easy DropDSA-150 Krüss, Germany) in the static sessile drop mode.

In the same sense, the topography of samples was acquired by AFM using a Keysight Model 5500 (Keysight Technologies, USA). Images were acquired via tapping mode in air using conical Si tips with a typical tip radius of $10 \mathrm{~nm}$ and length of $\sim 20 \mu \mathrm{m}$ (MPP-21120-10, Veeco, USA). The spring constant and resonance frequency were typically $3 \mathrm{Nm}^{-1}$ and $75-95 \mathrm{kHz}$, respectively. The root-mean-squared roughness $\left(\mathrm{R}_{\mathrm{RMS}}\right)$ of the surface was determined from imaging over $5 \times 5 \mu \mathrm{m}^{2}$ areas for each sample. AFM images and roughness calculations were processed using freely available software (Gwyddion V. 2.37).

Surface chemical compositions of our sample surfaces were determined by XPS. A surface analysis system (SPECS, Germany) equipped with a Phoibos 150 electron analyzer was used for the measurements. Monochromatized aluminum radiation $(1486.6 \mathrm{eV})$ with an output power set at $380 \mathrm{~W}$ was used for the analyses of all samples. The C1s signal $(284.6 \mathrm{eV})$ was employed as the reference to calibrate the binding energies (BE) of different elements in order to correct the charge effect. CasaXPS software was used to analyze all XPS data. Surface atomic concentrations in the samples were estimated using the instrument sensitivity factors to scale for the calculated photoelectron peak areas.

To record peptides adsorption on the PEI film, QCM-D analysis was performed (Q-Sense E4, Sweden), and the $\mathrm{QSoft}^{\mathrm{TM}}$ software was used to analyze raw data.

\subsection{Stability of the peptides immobilization}

PBS was used to study the stability of peptides immobilization on PEI substrate. Samples were placed in PBS solution while under stirring $\left(100 \mathrm{rpm}\right.$ ) in an orbital shaker at $37^{\circ} \mathrm{C}$ (Novatecnica, Ltda. Brazil) for 3, 6, 12 and $24 \mathrm{~h}$. Afterwards, samples were rinsed with distilled water and dried under a $\mathrm{N}_{2}$ flow. The stability of the immobilization was evaluated by measuring the water contact angle of the samples. The samples, incubated for $24 \mathrm{~h}$, were also analyzed by XPS technique and optical microscopy.

\subsection{Antibacterial assays}

For this study, two antibacterial assays were performed: the MIC calculation for both peptides and the spread plate counting method to determine the antibacterial effect of the immobilized peptides. Staphylococcus epidermidis (ATCC 12228) strain from INCQS - FIOCRUZ, Brazil, was used in both assays.

MICs of both peptides were determined by the agar dilution method as described by the guidelines from the Clinical Laboratory and Standards Institute [20]. Moreover, the analyses were based on the Fifteenth Informational Supplement of the Clinical Laboratory and Standards Institute [20]. Suspensions of peptides in non-inoculated medium (negative control), and a stock solution of rifampicin at $5 \mu \mathrm{g} / \mathrm{mL}$ (positive control), were prepared in distilled water $(20 \mu \mathrm{g} / \mu \mathrm{L})$. The tested compounds were sequentially diluted with BHI (Brain and Heart Infusion KASVI) medium in a 96 multiwell plate for a final volume of $100 \mu \mathrm{L} /$ well. An inoculum of $100 \mu \mathrm{L}$ of bacteria in BHI suspension at $1.0 \mathrm{McF}$ arland scale was added to each serial dilution in order to reach turbidimetric 0.5 McFarland $\left(\sim 1.5 \times 10^{8} \mathrm{CFU} / \mathrm{mL} ; \mathrm{CFU}=\right.$ Colony-Forming Units $)$ in a final volume of $200 \mu \mathrm{L} /$ well. The final concentrations of the compounds ranged from 10,000 to $0.062 \mu \mathrm{g} / \mu \mathrm{L}$. The multi-well plate was incubated for $18 \mathrm{~h}$ at $35-37^{\circ} \mathrm{C}$ in a humidity chamber. After incubation, $15 \mu \mathrm{L}$ of resazurin at $0.02 \%$ in sterile aqueous solution was added to each well. The measurements were performed after $24 \mathrm{~h}$ of reincubation. All assays were performed in triplicate.

The serial dilutions and plating technique were performed using aliquots of $1 \times 10^{6} \mathrm{CFU} / \mathrm{mL}$, which were inoculated in tryptic soy broth $(\mathrm{TSB})$ medium containing the samples $\left(1 \times 1 \mathrm{~cm}^{2}\right)$ in a safety cabinet (VLFS-12, Veco). The samples were incubated in triplicate for $24 \mathrm{~h}$ in a bacterial incubator (model AP-22, Phoenix) at $36^{\circ} \mathrm{C}$ without culture media replacement. At the end of the $24 \mathrm{~h}$ period, the culture medium was removed to interrupt all growth. The samples were subsequently washed three times with deionized water to completely remove the constituents of the culture medium as well as non-attached cells and biofilms. The samples were then submitted to ultra-sonication in PBS to remove the attached cells and they were consecutively diluted with PBS at a proportion of $1: 9 \mathrm{v} / \mathrm{v}$. Aliquots of $0.2 \mathrm{~mL}$ of the obtained cell suspensions were then plated in triplicate onto solid agar medium using the spread plate method. After incubating for $24 \mathrm{~h}$, the number of bacterial colonies was counted and the results, after multiplication by the dilution factor, were expressed as mean CFU per $\mathrm{cm}^{2}$. Bacterial cultures were performed in triplicate and survival rates were calculated by comparing $\mathrm{CFU} / \mathrm{cm}^{2}$ of samples with immobilized peptides using the PEI substrate as control. Data were analyzed statistically by analysis of variance (ANOVA) with subsequent Tukey post-hoc test using Statistica 12.0 software; $p$-values of .05 or less were considered statistically significant.

\subsection{Cytotoxicity assays}

Cytotoxicity assays were performed using the BALB/c 3T3 fibroblasts (National Institute of Health [NIH], Baltimore, USA) to verify if the immobilized peptides on PEI substrates presented any toxic effects. The cells were routinely grown in Roswell Park Memorial Institute (RPMI) medium supplemented with $10 \%$ fetal bovine serum, antibiotics ( $100 \mathrm{U} / \mathrm{mL}$ penicillin, $10 \mu \mathrm{g} / \mathrm{mL}$ streptomycin) and L-glutamine $(2 \mathrm{mM})$ in a humidified incubator with $5 \%$ carbon dioxide, at $37^{\circ} \mathrm{C}$. Aliquots of $10^{4}$ cells/well were incubated in 24well plates until reaching semiconfluence; the RPMI medium was then removed and substituted with fresh supplemented medium to culture the cells on samples $\left(1 \times 1 \mathrm{~cm}^{2}\right)$ for 24 and $72 \mathrm{~h}$. Cell viability was assessed by the MTT (3-(4,5-dimethylthiazol-2-yl)2,5-diphenyltetrazolium bromide) tetrazolium reduction assay. After the respective culture time, the samples were rinsed with PBS solution and $100 \mu \mathrm{L}$ of MTT solution $(0.5 \mathrm{mg} / \mathrm{mL}$ of culture medium) was added to each sample. After incubation for $4 \mathrm{~h}$ at $37^{\circ} \mathrm{C}$, the medium was removed and the formed crystals solubilized in $100 \mu \mathrm{L}$ of ethanol. The samples were shaken for $1 \mathrm{~min}$ on a plate shaker and the absorbance was measured at $570 \mathrm{~nm}$ in a microplate reader (ELx800, BioTek Instruments, Inc., USA) [21]. Cell viability data were expressed as the mean \pm SD of experiments. A percentage of viability compared with the control, PEI substrates (the mean optical density of cells was set to $100 \%$ viability), was calculated from the concentration-response curves by linear regression analysis. Cell cultures were performed in triplicate and data from each assay were analyzed statistically by analysis of variance (ANOVA) with subsequent Tukey post-hoc test using the Statistica 12.0 software; $p$-values of .05 or less were considered statistically significant. 
A

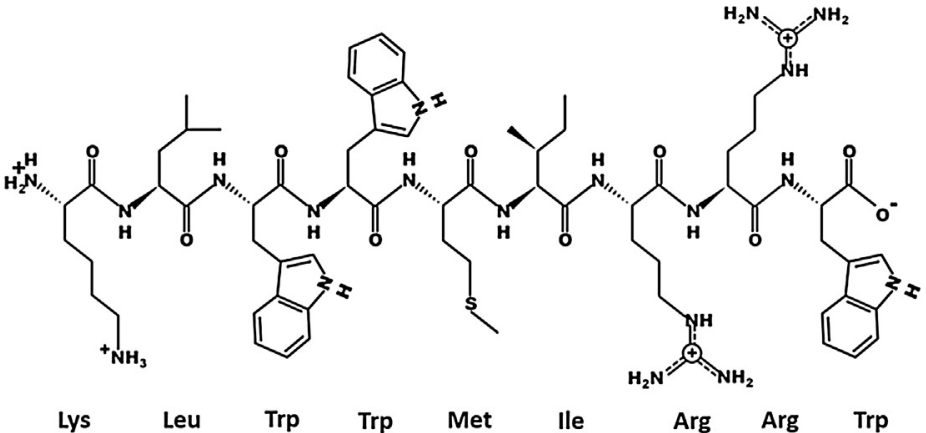

B

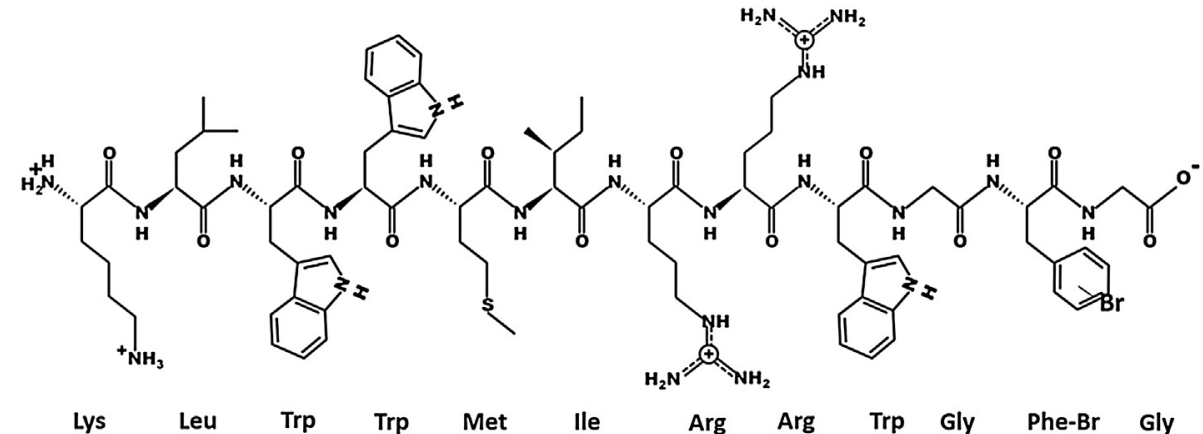

C

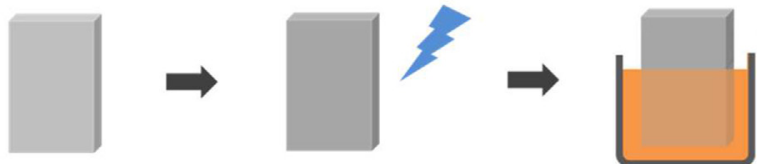

Si substrate

Oxidation

D

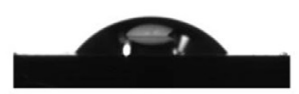

Si $53 \pm 5^{\circ}$

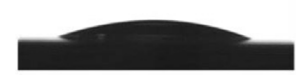

$\mathrm{SiO}_{2} \quad 11 \pm 4^{\circ}$
PEI film by dip coating

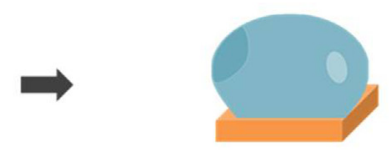

Peptides immobilization

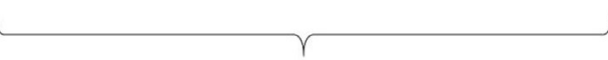

Pre-treatment

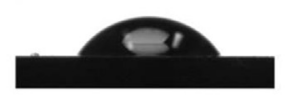

PEI $59 \pm 5^{\circ}$

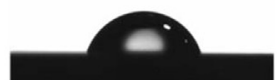

$\mathrm{PEI} / \mathrm{Tet}-12474 \pm 3^{\circ}$

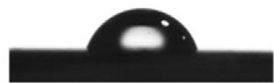

$\mathrm{PEI} / \mathrm{Tet}-124-\mathrm{Br} 72 \pm 4^{\circ}$

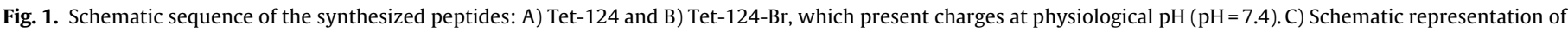
the peptide immobilization process. C) Monitoring of the peptide immobilization process by water contact angle technique.

\section{Results and discussion}

The amino acid structures of the synthetized peptides are represented in Fig. $1 \mathrm{~A}$ and $\mathrm{B}$. The Tet-124 peptide sequence (KLWWMIRRW) generated a molar weight of $1374.3 \mathrm{~g} / \mathrm{mol}$. Tet124-Br peptide (KLWWMIRRWG-(F-Br)-G) was obtained by adding 4-Bromophenylalanine to the rest of the original peptide structure by means of a glycine. Therefore, the molar weight of Tet-124-Br was higher than Tet-124: $1716.4 \mathrm{~g} / \mathrm{mol}$. It is important to note that both peptides were synthetized with a high content of cationic and hydrophobic amino acids [29] in order to make them antibacterial [3].

Fig. 1C illustrates the schematic representation of the peptides immobilization process, and Fig. 1D shows the respective monitoring, which was performed by water contact angle measurements. When the silicon wafer was oxidized by $\mathrm{O}_{2}$ plasma, its surface changed from hydrophobic to a strong hydrophilic behavior due to the generation of silica and silanol groups [22]. Upon coating with the PEI film, the water contact angle was increased, but the hydrophilic character was maintained due to the aminated groups of the polymer [23]. After the peptides immobilization, the water contact angle of the surface increased. This suggests that both peptides could electrostatically interact via their carboxylic groups with the amino groups of PEI, which would orient to the top surface their positive amino acid residues. According to Fig. $1 \mathrm{~A}$ and $\mathrm{B}$, carboxylic groups of the C-terminal residues of tryptophan (Trp) and glycine (Gly) would be available in Tet-124 and Tet-124-Br peptides, respectively. It should be mentioned that contact angle values for samples with immobilized peptides (PEI/Tet-124 and $\mathrm{PEI} / \mathrm{Tet}-124-\mathrm{Br}$ ) did not show any significant difference.

The topography and roughness of the samples were evaluated by AFM. Fig. 2 presents the 3D and 2D AFM images of the PEI substrate, PEI/Tet-124 and PEI/Tet-124-Br samples. The PEI substrate showed a textured surface, but with a low $R_{R M S}$ of $1.0( \pm 0.2) \mathrm{nm}$. In the 


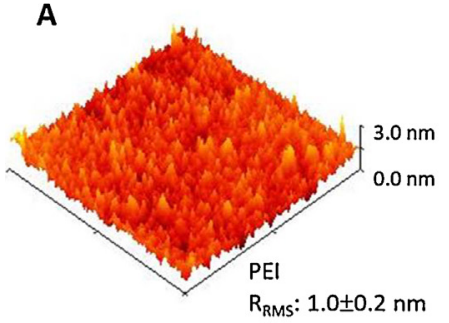

D

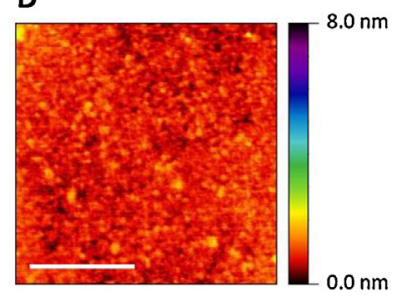

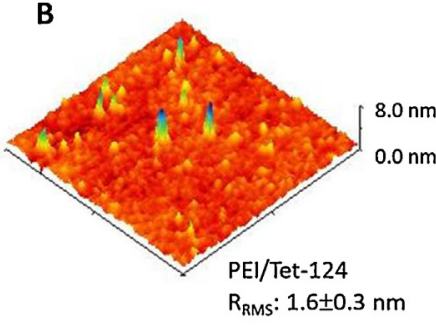

E

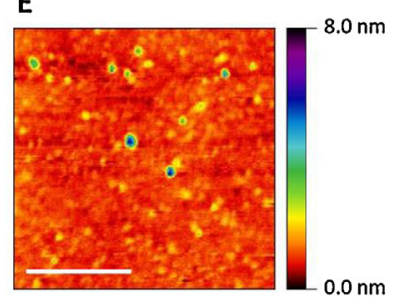

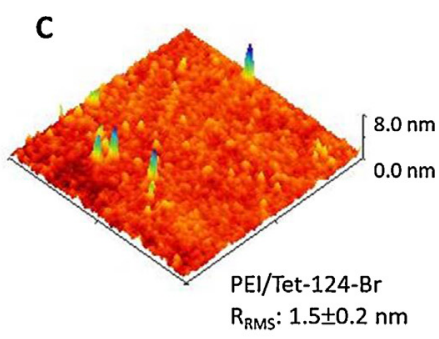

$\mathbf{F}$

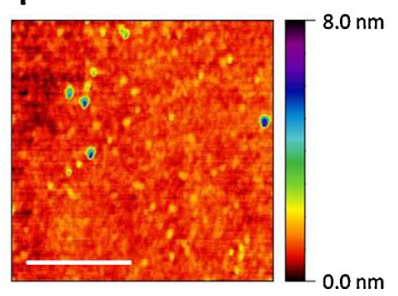

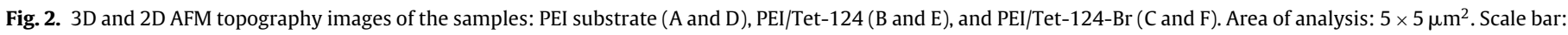
$2 \mu \mathrm{m}$.

Table 1

XPS data from the peptide immobilization: measured binding energies, atomic percentages and atomic ratios. Additionally, contributions to the C1s signal obtained after deconvolution are listed: measured binding energies and corresponding percentages. Reported values represent peak area percentage \pm standard deviation obtained from wide XPS scans of three different regions. In the case of atomic ratio, uncertainty propagation was applied.

\begin{tabular}{llll}
\hline Signal & PEI & PEI/Tet-124 & PEI/Tet-124-Br \\
\hline O1s & $530.7 \mathrm{eV}$ & $530.8 \mathrm{eV}$ & $530.8 \mathrm{eV}$ \\
& $30.1( \pm 0.3) \%$ & $29.5( \pm 0.3) \%$ & $27.5( \pm 0.3) \%$ \\
$\mathrm{C} 1 \mathrm{~s}$ & $287.7 \mathrm{eV}$ & $283.8 \mathrm{eV}$ & $284.8 \mathrm{eV}$ \\
& $22.5( \pm 0.2) \%$ & $28.4( \pm 0.3) \%$ & $31.2( \pm 0.3) \%$ \\
$\mathrm{~N} 1 \mathrm{~s}$ & $398.7 \mathrm{eV}$ & $398.8 \mathrm{eV}$ & $398.8 \mathrm{eV}$ \\
& $4.4( \pm 0.1) \%$ & $3.7( \pm 0.1) \%$ & $5.7( \pm 0.1) \%$ \\
$\mathrm{Si} 2 \mathrm{p}$ & $97.7 \mathrm{eV}$ & $97.8 \mathrm{eV}$ & $98.8 \mathrm{eV}$ \\
& $42.1( \pm 0.4) \%$ & $36.8( \pm 0.4) \%$ & $35.6( \pm 0.4) \%$ \\
Atomic ratio & & & \\
O/Si & $0.72( \pm 0.01)$ & $0.80( \pm 0.01)$ & $0.77( \pm 0.01)$ \\
$\mathrm{C} / \mathrm{Si}$ & $0.53( \pm 0.01)$ & $0.77( \pm 0.01)$ & $0.88( \pm 0.01)$ \\
$\mathrm{N} / \mathrm{Si}$ & $0.10( \pm 0.003)$ & $0.10( \pm 0.003)$ & $0.16( \pm 0.003)$ \\
$\mathrm{C} 1 \mathrm{~s} \mathrm{contribution})$ & & \\
$\mathrm{C}_{1}$ & $285.2 \mathrm{eV}$ & $285.0 \mathrm{eV}$ & $285.0 \mathrm{eV}$ \\
& $50( \pm 0.5) \%$ & $62.8( \pm 0.6) \%$ & $55.7( \pm 0.6) \%$ \\
$\mathrm{C}_{2}$ & $286.4 \mathrm{eV}$ & $286.5 \mathrm{eV}$ & $286.3 \mathrm{eV}$ \\
& $37.7( \pm 0.4) \%$ & $22.5( \pm 0.2) \%$ & $27.1( \pm 0.3) \%$ \\
$\mathrm{C}_{3}$ & $288.2 \mathrm{eV}$ & $287.9 \mathrm{eV}$ & $288.7 \mathrm{eV}$ \\
& $11.3( \pm 0.1) \%$ & $14.6( \pm 0.1) \%$ & $17.3( \pm 0.2) \%$ \\
\hline
\end{tabular}

case of PEI/Tet-124 and PEI/Tet-124-Br, samples presented larger roughness values than the control, $1.6( \pm 0.3)$ and $1.5 \mathrm{~nm}( \pm 0.2)$, respectively. Moreover, their surfaces were more heterogeneous with some randomly distributed peaks, which could be associated with local accumulation of peptides. PEI is used to promote uniform depositions of subsequent molecules, but a single film obtained by the dip coating technique is not completely homogenous; its surface can present some irregularities at the nanoscale level [24]. As peptides tend to aggregate and organize into large fibrils [25], those irregularities could present a higher charge that favors the aggregation of Tet peptides.

In order to provide further understanding of the mechanism of peptide immobilization, XPS analyses were performed. Table 1 presents the elemental surface compositions obtained after peptide immobilization: measured binding energies (BEs), atomic percentages, and atomic ratios. Atomic ratios between the various elements in the sample surface were calculated by using silicon ( $\mathrm{Si} 2 \mathrm{p})$ as ref- erence $(\mathrm{O} / \mathrm{Si}, \mathrm{C} / \mathrm{Si}$ and $\mathrm{N} / \mathrm{Si}$ ) [26]. Moreover, contributions to the C1s signal measured by XPS and obtained after deconvolution are also reported: measured binding energies and corresponding percentages. The $\mathrm{C} 1 \mathrm{~s}$ signal presented three contributions that can be attributed to $\mathrm{C}-\mathrm{C} / \mathrm{C}-\mathrm{H}\left(\mathrm{C}_{1}\right), \mathrm{C}-\mathrm{N} / \mathrm{C}-\mathrm{OH}\left(\mathrm{C}_{2}\right)$ and $\mathrm{COO}^{-}\left(\mathrm{C}_{3}\right)$ [26-28]. Fig. 3A and $B$ shows the changes of atomic ratio and contributions to the $\mathrm{C} 1 \mathrm{~s}$ signal after peptide immobilization, respectively. For both samples, PEI/Tet-124 and PEI/Tet-124-Br, the O/Si and C/Si ratios increased with respect to PEI. For the N/Si ratio, PEI/Tet124 presented a similar value than for the control (PEI); however, $\mathrm{PEI} /$ Tet-124-Br showed a higher N/Si ratio. The atomic ratio increasing trend strongly suggests the incorporation of peptides on the PEI surface. Regarding C1s contributions (Fig. 3B), it is particularly apparent the increasing of carboxylic groups $\left(C_{3}\right)$, which are associated with the electrostatic immobilization of peptides. QCM-D measurements were used to confirm the peptides immobilization. Fig. $3 \mathrm{C}$ and D shows the PEI deposition on the silicon oxide coated quartz crystals and next, the peptides on the PEI layer. In the first 6 min the baseline is detected. The PEI was adsorbed forming a stable film against buffer rinsing, in approximately 2 min. Next, peptides were in contact with PEI; showing a layer formation and a steady state approximately in $5 \mathrm{~min}$. Fig. $3 \mathrm{C}$ shows that Tet124 peptides were partially removed. The mass adsorption of the Tet-124-Br was higher and more stable according to its higher frequency drop during the first minutes and no considerable changes after saturation. Due to the high dissipation shift during QMC-D analysis (data not shown), the density of peptides immobilized on the PEI substrate could not be estimated by standard analysis [29], however, the low frequency drop suggested the immobilization of thin peptides layers; as it was corroborated by the XPS results.

The stability of peptides immobilization is another important issue for the proposed applications. For this reason, the samples were incubated into PBS medium at $37^{\circ} \mathrm{C}$ for $24 \mathrm{~h}$ and their water contact angles were measured for different incubation times (Fig. 4A). As a result, roughly constant angles were observed during the first $6 \mathrm{~h}$; nevertheless, after $12 \mathrm{~h}$ both peptide samples exhibited a more hydrophilic character. Despite the smaller contact angle values observed during the last hours of incubation, both PEI/Tet124 and $\mathrm{PEI} / \mathrm{Tet}-124-\mathrm{Br}$ samples showed a higher water contact angle than the original PEI substrate, which suggests that peptides were attached on the substrate surface during the incubation time. The decreasing of the water contact angle can be explained by salt crystal formation from PBS incubation and/or peptides release. In 


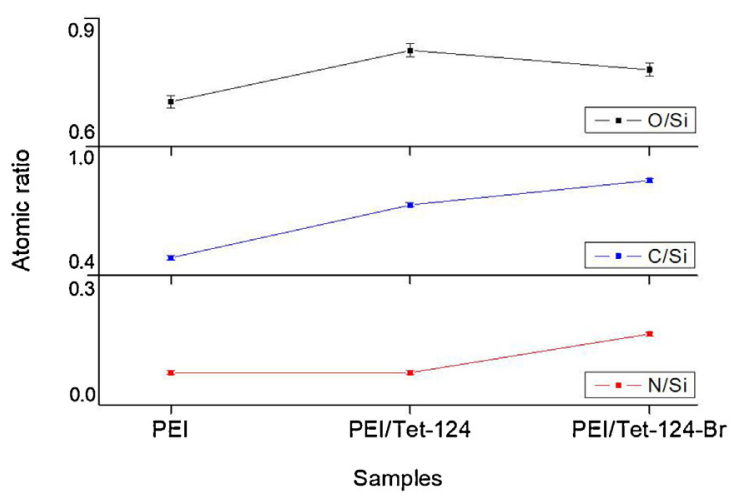

C

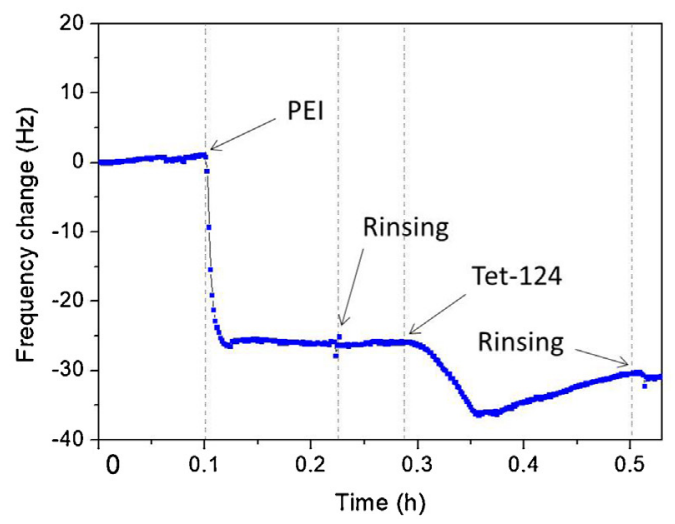

B

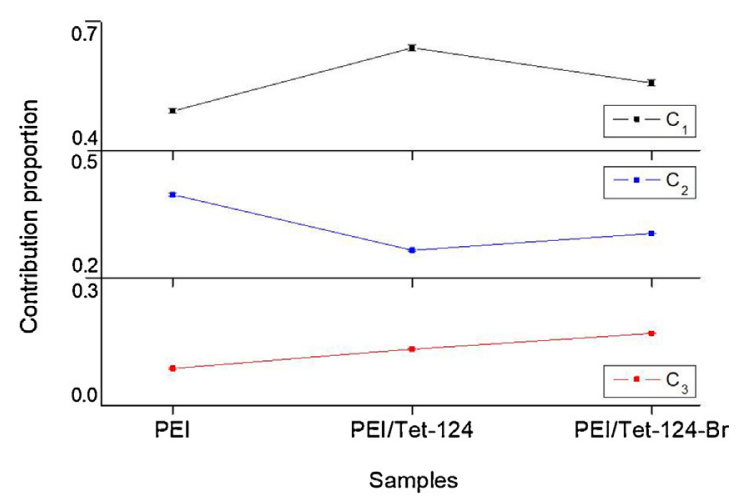

D

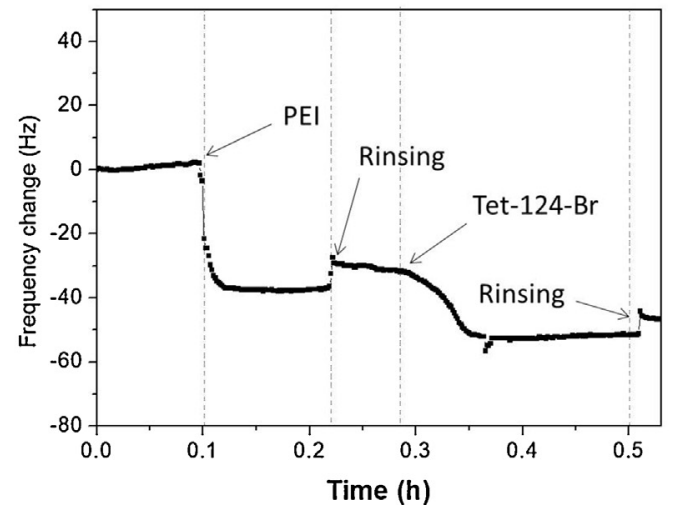

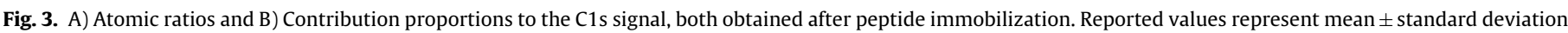

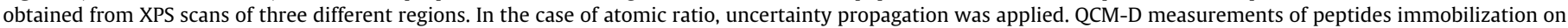
PEI: C) Tet-124 and D) Tet-124-Br.

A

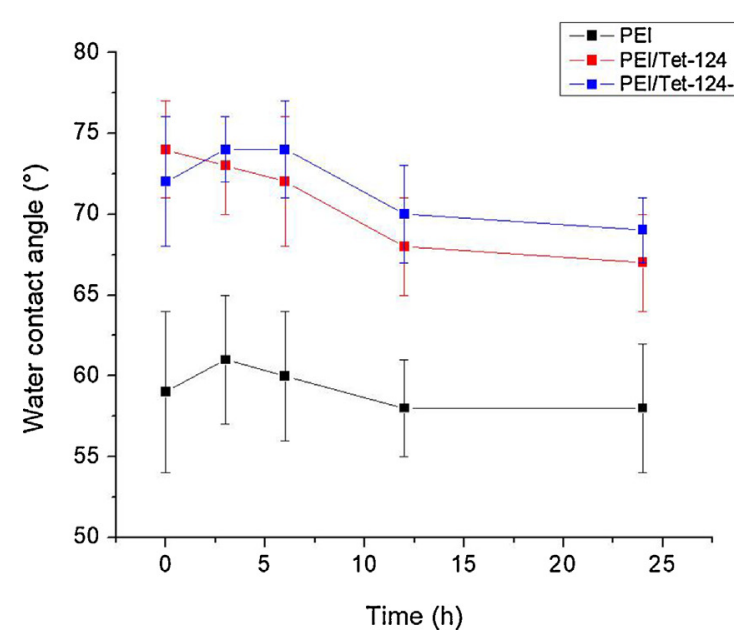

B

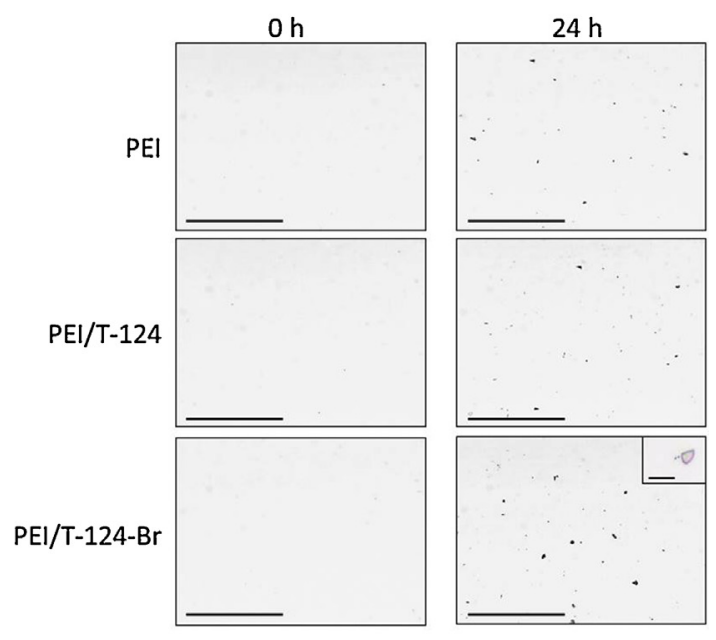

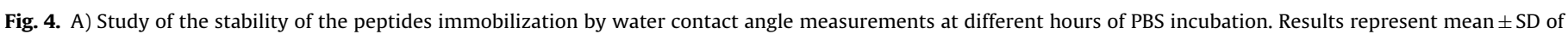
three measurements. B) Optical images of samples before and after $24 \mathrm{~h}$ of PBS incubation. Scale bars: $100 \mu \mathrm{m}$, inset scale bar: $10 \mu \mathrm{m}$.

that sense, Fig. 4B exhibits optical microscopic images of samples before and after $24 \mathrm{~h}$ of PBS incubation at $37^{\circ} \mathrm{C}$. The $24 \mathrm{~h}$-incubation series show micro-particles that can be associated to salt crystals. They are highly hygroscopic [30], and thus could reduce the water contact angle of the samples.

In order to verify the peptide release from the substrate surface, samples incubated into PBS medium were also analyzed by
XPS technique. Table 2 presents the elemental surface composition obtained before and after PBS incubation: measured BEs, atomic percentages, and atomic ratios. Additionally, measured binding energies and corresponding percentages from contributions to the $\mathrm{C} 1 \mathrm{~s}$ signal are also reported. Fig. 5 shows the changes of atomic ratio and contributions to the $\mathrm{C} 1 \mathrm{~s}$ signal, before and after PBS incubation. For both samples with immobilized peptides, the $\mathrm{O} / \mathrm{Si}, \mathrm{C} / \mathrm{Si}$ and N/Si 
Table 2

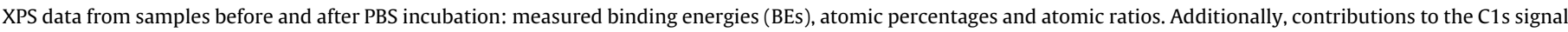

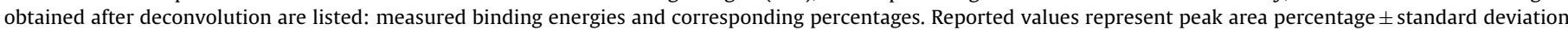
obtained from wide XPS scans of three different regions. In the case of atomic ratio, uncertainty propagation was applied.

\begin{tabular}{|c|c|c|c|c|}
\hline Signal & PEI/Tet-124 & PEI/Tet-124 in PBS & $\mathrm{PEI} / \mathrm{Tet}-124-\mathrm{Br}$ & $\mathrm{PEI} / \mathrm{Tet}-124-\mathrm{Br}$ in PBS \\
\hline \multirow[t]{2}{*}{ 01s } & $530.8 \mathrm{eV}$ & $530.8 \mathrm{eV}$ & $530.8 \mathrm{eV}$ & $530.8 \mathrm{eV}$ \\
\hline & $29.5( \pm 0.3) \%$ & $30.6( \pm 0.3) \%$ & $27.5( \pm 0.3) \%$ & $27.6( \pm 0.3) \%$ \\
\hline \multirow[t]{2}{*}{$\mathrm{C} 1 \mathrm{~s}$} & $283.8 \mathrm{eV}$ & $284.8 \mathrm{eV}$ & $284.8 \mathrm{eV}$ & $283.8 \mathrm{eV}$ \\
\hline & $28.4( \pm 0.3) \%$ & $23.1( \pm 0.2) \%$ & $31.2( \pm 0.3) \%$ & $22.2( \pm 0.2) \%$ \\
\hline \multirow[t]{2}{*}{ N1s } & $398.8 \mathrm{eV}$ & $398.8 \mathrm{eV}$ & $398.8 \mathrm{eV}$ & $398.8 \mathrm{eV}$ \\
\hline & $3.7( \pm 0.1) \%$ & $3.7( \pm 0.1) \%$ & $5.7( \pm 0.1) \%$ & $4.2( \pm 0.1) \%$ \\
\hline \multirow[t]{2}{*}{ Si2p } & $97.8 \mathrm{eV}$ & $97.8 \mathrm{eV}$ & $98.8 \mathrm{eV}$ & $97.8 \mathrm{eV}$ \\
\hline & $36.8( \pm 0.4) \%$ & $42.2( \pm 0.4) \%$ & $35.6( \pm 0.4) \%$ & $41.7( \pm 0.4) \%$ \\
\hline \multicolumn{5}{|c|}{ Atomic ratio } \\
\hline $\mathrm{O} / \mathrm{Si}$ & $0.80( \pm 0.01)$ & $0.73( \pm 0.01)$ & $0.77( \pm 0.01)$ & $0.66( \pm 0.01)$ \\
\hline $\mathrm{C} / \mathrm{Si}$ & $0.77( \pm 0.01)$ & $0.55( \pm 0.01)$ & $0.88( \pm 0.01)$ & $0.53( \pm 0.01)$ \\
\hline $\mathrm{N} / \mathrm{Si}$ & $0.10( \pm 0.003)$ & $0.09( \pm 0.003)$ & $0.16( \pm 0.003)$ & $0.10( \pm 0.003)$ \\
\hline \multicolumn{5}{|c|}{ C1s contributions } \\
\hline \multirow[t]{2}{*}{$\mathrm{C}_{1}$} & $285.0 \mathrm{eV}$ & $285.2 \mathrm{eV}$ & $285.0 \mathrm{eV}$ & $285.1 \mathrm{eV}$ \\
\hline & $62.8 \%( \pm 0.6)$ & $73.9 \%( \pm 0.7)$ & $55.7 \%( \pm 0.6)$ & $59.8 \%( \pm 0.6)$ \\
\hline \multirow[t]{2}{*}{$\mathrm{C}_{2}$} & $286.5 \mathrm{eV}$ & $286.9 \mathrm{eV}$ & $286.3 \mathrm{eV}$ & $286.3 \mathrm{eV}$ \\
\hline & $22.5 \%( \pm 0.2)$ & $26.1 \%( \pm 0.3)$ & $27.1 \%( \pm 0.3)$ & $27.8 \%( \pm 0.3)$ \\
\hline \multirow[t]{2}{*}{$\mathrm{C}_{3}$} & $287.9 \mathrm{eV}$ & - & $288.7 \mathrm{eV}$ & $288.2 \mathrm{eV}$ \\
\hline & $14.6 \%( \pm 0.1)$ & & $17.3 \%( \pm 0.2)$ & $12.4 \%( \pm 0.1)$ \\
\hline
\end{tabular}

A

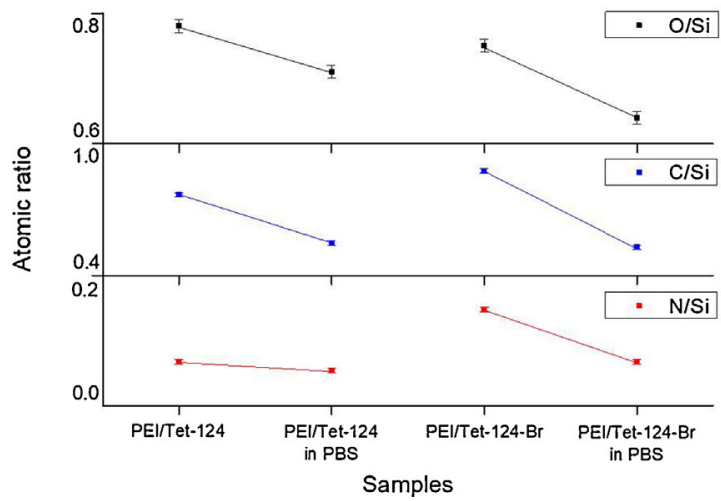

B

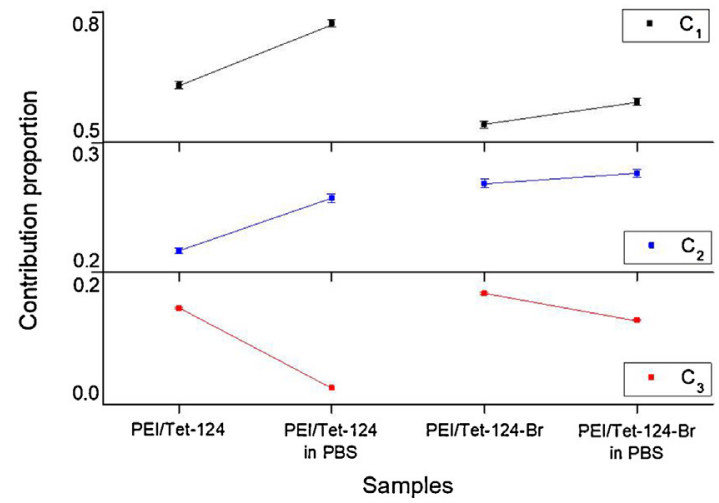

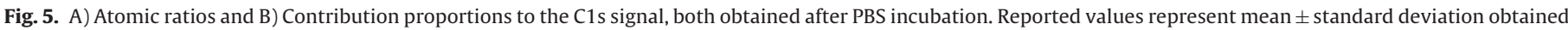
from three different XPS scans areas. In the case of atomic ratio, uncertainty propagation was applied.

ratios decreased with respect to the PEI substrate (Fig. 5A), as well as the signal related to carboxylic groups ( $\mathrm{C}_{3}$ of $\mathrm{C} 1 \mathrm{~s}$ contributions). These results can be interpreted as a partial peptide release at the final incubation stages.

After physicochemical characterization and evaluation of the stability of the peptides immobilization, the antibacterial activity of samples was assessed. First, the MIC of peptides in solution was obtained: $50 \mu \mathrm{g} / \mathrm{mL}(36.4 \mu \mathrm{M})$ for Tet-124 and $100 \mu \mathrm{g} / \mathrm{mL}$ $(58.3 \mu \mathrm{M})$ for Tet-124-Br, respectively. Afterwards, the antibacterial effect of the immobilized peptides on PEI was tested (Fig. 6A). In comparison to the PEI control, after $24 \mathrm{~h}$ of culture the survival of bacteria was $23 \%$ for PEI/Tet-124 and 34\% for PEI/Tet-124$\mathrm{Br}$ (77\% and $66 \%$ of bacterial inhibition, respectively). Comparing the antibacterial effect between both samples, PEI/Tet-124-Br was $\sim 50 \%$ less effective than PEI/Tet-124. These findings agree with the obtained MIC values; in terms of micro-molar concentrations $\mathrm{PEI} /$ Tet-124-Br was $\sim 60 \%$ less effective than PEI/Tet-124. Compared with peptides in solution, results of antibacterial assays showed a reduction of the antibacterial activity of peptides originated by the immobilization process [31], which reduce interaction of the peptides with the microorganisms. Moreover, although the aggregation of peptides observed on the substrate surface is lower than 5\% (2D AFM images of Fig. 2), this could also reduce their antibac- terial effect because the positive amino acid residues of peptide molecules could not be completely oriented to the surface top, but rather interact between the peptide molecules themselves.

In general, due to the different parameters involved in the immobilization of AMPs, it is difficult to quantitatively compare performances in the literature. One of the bottlenecks is the large diversity of AMPs; so far, more than 2000 such molecules have been reported in the antimicrobial peptide database (http://aps.unmc. edu/AP/main.php) [32]. Furthermore, different methods based on physical or chemical immobilization of AMPs have been explored to develop antibacterial coatings, which were tested on several types of bacteria, such as Pseudomonas aeruginosa, Staphylococcus aureus, Escherichia coli, Klebsiella pneumoniae, Micrococcus luteus, et cetera [32]. However, if we consider immobilized peptides that were tested against Staphylococcus epidermidis, we find in the literature reports with antibacterial activity similar or higher than our work. For example, Shi et al. [33] immobilized Arg-Gly-Asp peptides on chitosan-grafted titanium substrates through covalent binding and they reported a decreasing of S. epidermidis adhesion by $85 \%$ after $4 \mathrm{~h}$ of incubation. On the other hand, Antoci et al. [34] covalently attached vancomycin (a glycopeptide antibiotic) to Ti alloy surface and the $S$. epidermidis colonization was totally inhibited after up to $30 \mathrm{~h}$ of culture $(<99 \%)$. Nevertheless, our work showed a single 
A

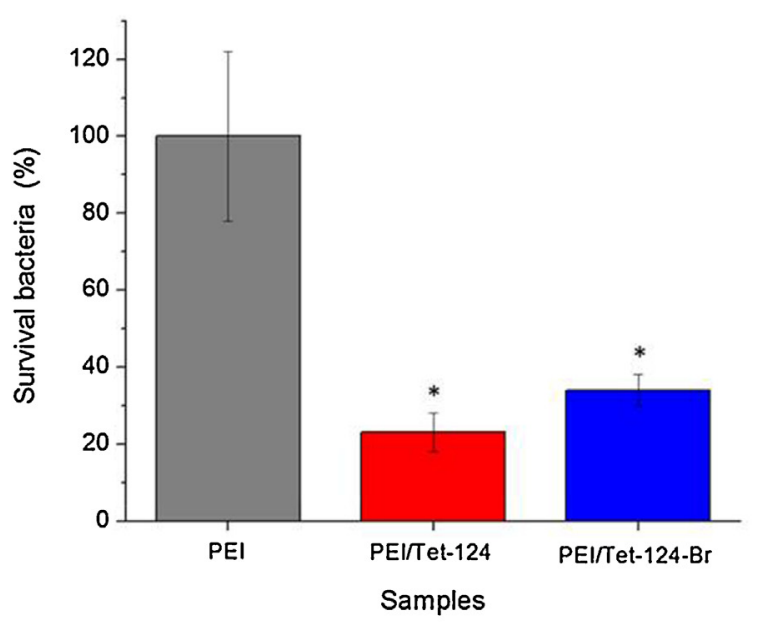

C

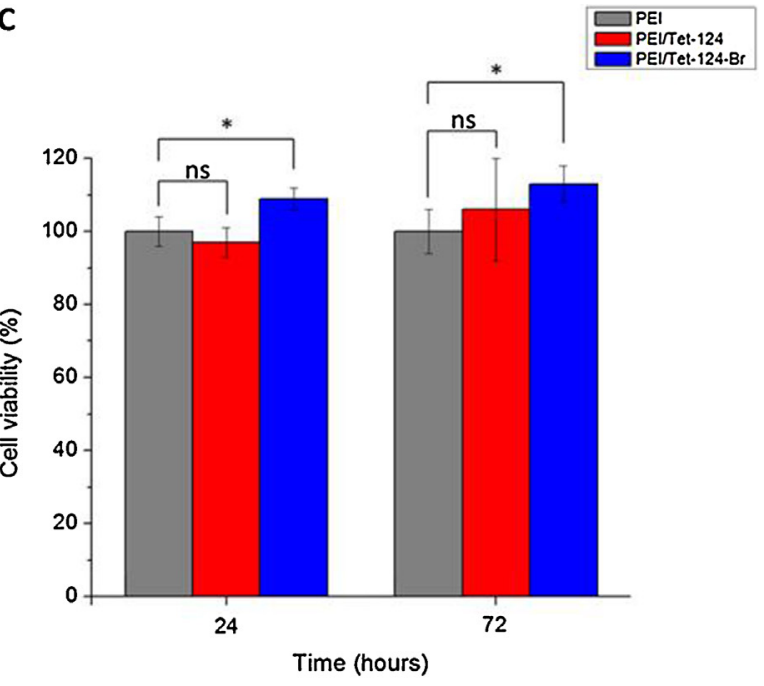

B

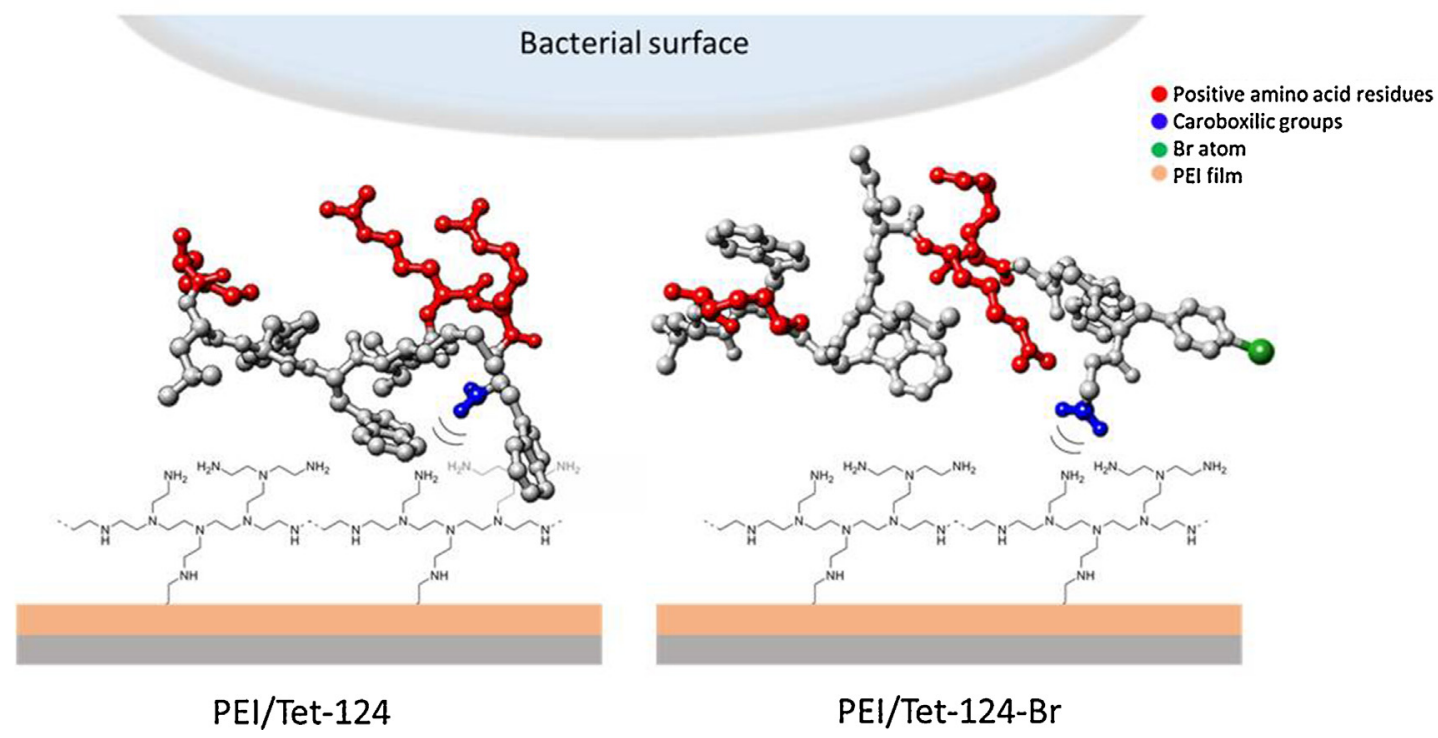

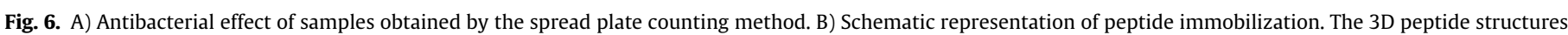

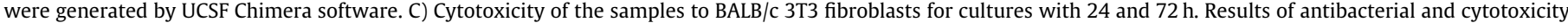

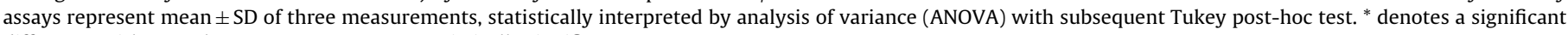
difference with a $p$-value $\leq .05$. ns means not statistically significant.

process to electrostatically immobilize Tet-124 peptides, with good antimicrobial performance up to $24 \mathrm{~h}$ for biomedical applications. In that sense, our results provide solid ground to pursue enhanced design and synthesis of Tet-124 peptides as an antibacterial agent.

By contrast, when the samples were compared to each other, the differentiated structure of Tet-124-Br, the Phe-Br linked by Gly, decreased the antibacterial activity of Tet-124. This suggests that the 3D conformation of Tet-124-Br exhibited less spatial availability of its positive amino acid residues to interact with the bacteria surface than Tet-124. This model was supported by building the 3D structure of peptides using the UCSF Chimera software (Fig. 6B). According to the previous results of surface characterizations, both peptides would be mainly linked to PEI film by the electrostatic interactions of carboxylic/amino groups, but hydrogen bonds could also contribute to the process of peptide immobilization [35]. In the case of PEI/Tet-124, the positive amino acid residues of the peptide would be oriented to the top surface, resulting in a large killing effect against the bacteria. However, for the case of PEI/Tet-124-
$\mathrm{Br}$, its positive amino acid residues would be screened and unable to totally interact with the bacteria surface, reducing its antibacterial effect. Although the peptide molecules could be randomly arranged on the surface of the PEI film, they should keep the proposed orientation because of their rigid and planar amide bonds [36].

Finally, the cytotoxicity of PEI substrate (as control) and surfaces with immobilized peptides (PEI/Tet-124 and PEI/Tet-124-Br) was studied using BALB/c 3T3 fibroblasts by the MTT colorimetric assay for 24 and $72 \mathrm{~h}$ (Fig. 6C). During the first $24 \mathrm{~h}$ of culture, PEI/Tet-124 presented a slight reduction of $\sim 3 \%$ in the cell viability, in contrast to the PEI/Tet-124-Br that showed an increase of $\sim 10 \%$ in the cell viability. At 72 h of culture, $\mathrm{PEI} / \mathrm{Tet}-124$ recovered and even reached $\sim 106 \%$ of cell viability, and PEI/Tet-124-Br presented the higher cell viability of $\sim 113 \%$. Therefore, it can be concluded that samples were not cytotoxic for fibroblast cells up to $72 \mathrm{~h}$. It is interesting to highlight that previous bacteria culture profiles agree with these cell culture profiles: PEI/Tet-124 presented the higher antibacte- 
rial effect and, though it did not show cytotoxicity, exhibited lower cell viability. However, PEI/Tet-124-Br presented a lower antibacterial effect but higher cell viability. This could confirm that the positive amino acid residues of PEI/Tet-124 are effectively oriented to the top surface, interacting with the cell surface as well. However, cell viability first decreased at $24 \mathrm{~h}$ and then increased at $72 \mathrm{~h}$ for PEI/Tet-124, which can be considered a temporary inhibition of proliferation due to adaptation mechanisms of the cells to this surface [24]. For the case of PEI/Tet-124-Br, the sample presented the lower antibacterial effect but the higher cell viability, possibly because the positive amino acid residues are not completely oriented to the surface top, thus exhibiting diminished interaction with both $S$. epidermidis bacteria and fibroblast cells.

\section{Conclusions}

Two kinds of Tet-124 peptides were immobilized on a PEI film: Tet-124 (KLWWMIRRW) and Tet-124-Br (KLWWMIRRWG-(F-Br)$\mathrm{G})$. The immobilization occurred due to the electrostatic interaction between amino groups of PEI and carboxylic groups of Trp and Gly amino acids of Tet-124 and Tet-124-Br peptides, respectively. The process was monitored by water contact angle, AFM and QCM-D measurements. The immobilization mechanism and its stabilization were studied using XPS analyses. For S. epidermidis cultures after $24 \mathrm{~h}, \mathrm{PEI} / \mathrm{Tet}-124$ presented a higher antibacterial effect than $\mathrm{PEI} / \mathrm{Tet}-124-\mathrm{Br}$, a behavior attributed to the better orientation of the Tet-124 peptide positive amino acid residues to the top surface, resulting in a higher killing effect against the bacteria. Finally, both samples did not present cytotoxicity for fibroblasts for up to $72 \mathrm{~h}$. These results suggest that it may be feasible to electrostatically immobilize Tet-124 peptides on PEI films for biomedical applications, such as protecting prosthesis against $S$. epidermidis contamination.

\section{Acknowledgments}

We acknowledge the Brazilian Nanotechnology National Laboratory (LNNano, CNPEM) for access to their XPS facilities. This work was financially supported by FAPESP (grants \# 2013/14888-3 and 2015/16611-4), CNPq and CAPES.

\section{Appendix A. Supplementary data}

Supplementary data associated with this article can be found, in the online version, at https://doi.org/10.1016/j.colsurfb.2018.02. 002.

\section{References}

[1] V. Sambhy, M.M. MacBride, B.R. Peterson, A. Sen, J. Am. Chem. Soc. 128 (2006) 9798-9808.

[2] C. de la Fuente-Nunez, V. Korolik, M. Bains, U. Nguyen, E.B. Breidenstein, S, Horsman, et al., Antimicrob. Agents Chemother. 56 (2012) 2696-2704.
[3] D.M. Easton, A. Nijnik, M.L. Mayer, R.E. Hancock, Trends Biotechnol. 27 (2009) $582-590$.

[4] B. Bechinger, K. Lohner, Biochim. Biophys. Acta (BBA)-Biomembr. 1758 (2006) 1529-1539.

[5] S.J. Lam, N.M. O'Brien-Simpson, N. Pantarat, A. Sulistio, E.H. Wong, Y. Chen, et al., Nat. Microbiol. (2016) 1-11.

[6] S. Hou, Z. Liu, A.W. Young, S.L. Mark, N.R. Kallenbach, D. Ren, Appl. Environ. Microbiol. 76 (2010) 1967-1974.

[7] S. Maria-Neto, K.C. de Almeida, M.L.R. Macedo, O.L. Franco, Biochim. Biophys. Acta (BBA)-Biomembr. 1848 (2015) 3078-3088.

[8] W.C. Wimley, ACS Chem. Biol. 5 (2010) 905-917.

[9] L.T. Nguyen, E.F. Haney, H.J. Vogel, Trends Biotechnol. 29 (2011) 464-472.

[10] F. Guilhelmelli, N. Vilela, P. Albuquerque, LdS Derengowski, I. Silva-Pereira, C.M. Kyaw, Front. Microbiol. 4 (2013) 63-74.

[11] A. Shukla, K.E. Fleming, H.F. Chuang, T.M. Chau, C.R. Loose, G.N. Stephanopoulos, et al., Biomaterials 31 (2010) 2348-2357.

[12] Y.R. Corrales Ureña, L. Wittig, M.V. Nascimento, J.L. Faccioni, P.N. Lisboa Filho, K. Rischka, Appl. Adhes. Sci. 3 (2015) 1.

[13] L. Townsend, R.L. Williams, O. Anuforom, M.R. Berwick, F. Halstead, E. Hughes et al., J. R. Soc. Interface 14 (2017) 20160657.

[14] Q. Lu, E. Danner, J.H. Waite, J.N. Israelachvili, H. Zeng, D.S. Hwang, J. R. Soc. Interface 10 (2013) 20120759.

[15] K. Hilpert, M. Elliott, H. Jenssen, J. Kindrachuk, C.D. Fjell, J. Körner, et al., Chem. Biol. 16 (2009) 58-69.

[16] S. Donatan, M. Sarikaya, C. Tamerler, M. Urgen, J. R. Soc. Interface 9 (2012) 2688-2695.

[17] J.E. Baio, T. Weidner, D. Ramey, L. Pruzinsky, D.G. Castner, Biointerphases 8 (2013) 18.

[18] F. Gomes, P. Teixeira, R. Oliveira, Biofouling 30 (2014) 131-141.

[19] N. Sharma, R. Furter, P. Kast, D.A. Tirrell, FEBS Lett. 467 (2000) 37-40.

[20] CLSI, Clinical Laboratory Standards Institute, Mo2-A12 Performance Standards for Antimicrobial Disk Susceptibility Tests; Approved Standard, 12th ed., National Committee for Clinical Laboratory Standards, Wayne, USA, 2015.

[21] B. Lopez, C. de Lourenço, D. Alves, D. Machado, M. Lancellotti, A. Sawaya, J. Appl. Microbiol. 119 (2015) 677-687.

[22] N. Naveas, V.T. Costa, D. Gallach, J. Hernandez-Montelongo, R.J.M. Palma, J.P. Garcia-Ruiz, et al., Sci. Technol. Adv. Mater. 13 (2012) 045009.

[23] J. Hernandez-Montelongo, E. Lucchesi, I. Gonzalez, W. Macedo, V. Nascimento, A. Moraes, et al., Colloids Surf. B: Biointerfaces 141 (2016) 499-506.

[24] J. Hernandez-Montelongo, E. Lucchesi, V. Nascimento, C. França, I. Gonzalez W. Macedo, et al., Mater. Sci. Eng.: C 71 (2016) 718-724.

[25] Q. Wang, N. Shah, J. Zhao, C. Wang, C. Zhao, L. Liu, et al., Phys. Chem. Chem. Phys. 13 (2011) 15200-15210.

[26] G. Iucci, C. Battocchio, M. Dettin, F. Ghezzo, G. Polzonetti, Solid State Sci. 12 (2010) 1861-1865.

[27] J.S. Stevens, A.C. Luca, M. Pelendritis, G. Terenghi, S. Downes, S.L. Schroeder Surf. Interface Anal. 45 (2013) 1238-1246.

[28] P. Gentile, C. Ghione, C. Tonda-Turo, D. Kalaskar, RSC Adv. 5 (2015) 80039-80047.

[29] A.K. Srivastava, P. Sakthivel, J. Vac. Sci. Technol. A 19 (2001) 97-100.

[30] Y. Wang, B. Jing, Y. Guo, J. Li, S. Tong, Y. Zhang, et al., J. Environ. Sci. 45 (2016) $156-163$.

[31] M. Bagheri, M. Beyermann, M. Dathe, Antimicrob. Agents Chemother. 53 (2009) 1132-1141.

[32] D. Alves, M. Olívia Pereira, Biofouling 30 (2014) 483-499.

[33] Z. Shi, K. Neoh, E. Kang, C. Poh, W. Wang, J. Biomed. Mater. Res. Part A 86 (2008) 865-872.

[34] V. Antoci, C.S. Adams, J. Parvizi, H.M. Davidson, R.J. Composto, T.A. Freeman, et al., Biomaterials 29 (2008) 4684-4690.

[35] V. Puddu, C.C. Perry, Langmuir 30 (2013) 227-233.

[36] J. Berg, J. Tymoczko, L. Stryer (Eds.), Biochemistry, 5th ed., W. H Freeman, New York, USA, 2002. 